\title{
CASOS INVESTIGATIVOS PARA LA PROMOÇIÓN DE LA INTERDISCIPLINARIEDAD ENTRE LA ENSEÑANZA DE LAS CIENCIAS Y LA LITERATURA BRASILEIRA /
}

\author{
Lucas Peres Guimarães \\ lucaspegui@hotmail.com \\ https://orcid.org/0000-0002-2226-3042 \\ Denise Leal de Castro \\ denise.castro@ifrj.edu.br \\ https://orcid.org/0000-0003-4572-4689 \\ Instituto Federal de Educação Ciência e Tecnologia do Rio de Janeiro - IFRJ
}

Brasil

Recibido: 2020-03-21; Aceptado: 2020-07-05

\section{Resumen}

Este trabajo aborda una estrategia didáctica de un caso de investigación para promover la interdisciplinariedad entre la enseñanza de la ciencia y la literatura brasileña aplicada a los estudiantes de la escuela primaria en una escuela pública. Investigamos la dinámica de las interacciones entre los estudiantes de un caso de investigación inspirado en las "Memórias Póstumas de Brás Cubas" de Machado de Assis, centrado en el desarrollo de las habilidades argumentales desarrolladas por Toulmin. En las clases de ciencia y literatura los alumnos analizaron el caso de Brás Cubas, protagonista de la obra, y el problema retratado estaba relacionado con el personaje central que intentaba inventar "el yeso de Brás Cubas", con el fin de curar a toda nuestra melancólica humanidad. Este dilema es central en la obra original de Machado de Assis y, en nuestra estrategia, fue decodificado en el formato de una carta con la intención de proporcionar una mayor comprensión al público objetivo, entre 13 y 14 años. A partir de la transposición didáctica, realizada en este clásico de la literatura brasileña, los alumnos analizaron si los medicamentos pueden resolver todos los males de la humanidad, y también discutieron cuestiones sociales y científicas como la ética en la industria farmacéutica y los casos de depresión, ansiedad y el uso de medicamentos de forma no regulada. El caso de investigación se llevó a cabo durante las cinco clases y se analizaron las actividades para identificar la eficacia de la argumentación y la colaboración de los estudiantes en la resolución del caso. La resolución se desarrolló en las clases con el fin de proporcionar interdisciplinariedad, implicando la presentación de la obra de Machado de Assis, la relación fosfoetanolamina (caso real) y el yeso Brás Cubas (caso ficticio) y la rueda de conversación. Las estrategias didácticas como la que se aborda en este estudio pueden ayudar a los estudiantes de la educación básica a aprender y aplicar los principales conceptos y habilidades propuestos, adquiriendo una postura activa durante la resolución del problema propuesto.

Palabras clave: Machado de Assis; cuestiones socio-científicas; ética farmacêutica; casos de investigación 


\title{
CASOS INVESTIGATIVOS PARA A PROMOÇÃO DA INTERDISCIPLINARIDADE ENTRE O ENSINO DE CIÊNCIAS E A LITERATURA BRASILEIRA
}

\section{Resumo}

Este trabalho aborda uma estratégia didática de um caso investigativo para promover a interdisciplinaridade entre o ensino de ciências e a literatura brasileira aplicado aos estudantes do Ensino Fundamental de uma escola pública. Investigamos a dinâmica das interações entre os alunos a partir de um caso investigativo inspirado na obra "Memórias Póstumas de Brás Cubas" de Machado de Assis, focado no desenvolvimento da habilidade de argumentação desenvolvido por Toulmin. Durante as aulas de ciências e literatura os alunos analisaram o caso de Brás Cubas, protagonista da obra, e o problema retratado era relativo ao personagem central que tentava inventar "o emplasto Brás Cubas", com o objetivo de curar toda nossa melancólica humanidade. Esse dilema é central na obra original de Machado de Assis e, em nossa estratégia, ele foi decodificado no formato de uma carta com a intenção de proporcionar maior compreensão ao público alvo, entre 13 e 14 anos. A partir da transposição didática, realizada nesse clássico da literatura brasileira, os estudantes analisaram se medicamentos podem resolver todos os males da humanidade, além disso discutiram questões sociocientíficas como a ética na indústria farmacêutica e os casos de depressão, ansiedade e o uso de medicamentos de modo desregrado. $\mathrm{O}$ caso investigativo foi realizado durante as cinco aulas e foram analisadas as atividades para identificar a eficácia da argumentação e da colaboração dos alunos na resolução do caso. A resolução foi desenvolvida nas aulas de modo a proporcionar a interdisciplinaridade, envolvendo apresentação da obra do Machado de Assis, relação da fosfoetanolamina (caso real) e o emplasto Brás Cubas (caso fíctício) e roda de conversa. Estratégias didáticas como a abordada em este estudo pode ajudar os estudantes da educação básica a aprender e aplicar os principais conceitos e habilidades propostos, adquirindo uma postura ativa durante a resolução do problema proposto.

Palavras-chave: Machado de Assis; questões sociocientíficas; ética farmacêutica, casos investigativos

\section{INVESTIGATIVE CASES FOR A PROMOÇÃO DA INTERDISCIPLINARIDADE BETWEEN OR ENSINO DE CIÊNCIAS E A LITERATURA BRASILEIRA}

\begin{abstract}
This work addresses a didactic strategy of an investigative case to promote interdisciplinarity between science teaching and Brazilian literature applied to primary school students in a public school. We investigate the dynamics of interactions between students from an investigative case inspired by the work "Memórias Póstumas de Brás Cubas" by Machado de Assis, focused on the development of argumentation skills developed by Toulmin. During science and literature classes the students analyzed the case of Brás Cubas, the protagonist of the work, and the problem portrayed was related to the central character who tried to invent "the Brás Cubas plaster", with the objective of curing all our melancholic humanity. This dilemma is central to Machado de Assis' original work and, in our strategy, it was decoded in the format of a letter with the intention of providing greater understanding to the target audience, between 13 and 14 years. From the didactic transposition, carried out in this classic of Brazilian literature, the students analyzed if medicines can solve all the ills of humanity, and also discussed social and scientific issues such as ethics in the pharmaceutical industry and cases of depression, anxiety and the use of medicines in an unregulated manner. The
\end{abstract}


investigative case was conducted during the five classes and activities were analyzed to identify the effectiveness of the argumentation and collaboration of the students in solving the case. The resolution was developed in the classes in order to provide interdisciplinarity, involving the presentation of Machado de Assis's work, phosphoethanolamine relationship (real case) and the Brás Cubas plaster (fictitious case) and conversation wheel. Didactic strategies such as the one approached in this study can help students in basic education to learn and apply the main concepts and skills proposed, acquiring an active posture during the resolution of the proposed problem.

Keywords: Machado de Assis; socio-scientific issues; pharmaceutical ethics; research cases

\section{Introdução}

A busca por recursos metodológicos para o ensino costuma ocupar de forma constante a atenção dos professores. Tal procura nos mobiliza e instiga, dando-nos a oportunidade de um trabalho que pode ser sempre renovado. Nesse percurso contínuo de pesquisa e criação, podemos também ampliar nossa compreensão acerca do campo de conhecimentos com o qual lidamos e, muitas vezes, é no exercício de nossa prática pedagógica que, de forma mais significativa, aprendemos as lições.

Este trabalho relaciona-se a essas buscas e a essas lições. Ele procura sintetizar os principais fundamentos teórico-metodológicos, análises e resultados de um estudo desenvolvido com o objetivo de investigar o papel potencializador da literatura na aprendizagem baseada em problemas, discutindo as aproximações entre as linguagens científica e literária e suas relações com o ensino e a aprendizagem.

No que concerne às abordagens baseadas em problemas na sala de aula, o uso da literatura brasileira leva narrativas intrigantes e contextualizadas que estimulam a criatividade, a exploração intelectual e a interação social em grupo.

O estudo em questão tomou como base o livro memórias póstumas de Brás Cubas, escrita por Machado de Assim em, 1881. A obra é realizada através de uma narração que é feita em primeira pessoa e postumamente, ou seja, o narrador se auto intitula um defunto-autor - um morto que resolveu escrever suas memórias. Assim, temos toda uma vida, contada por alguém que não pertence a realidade terrena. Com esse procedimento, o narrador consegue ficar além de nosso julgamento terreno e, desse modo, pode contar as memórias da forma como melhor lhe convém.

O romance não apresenta grandes feitos, não há um acontecimento significativo que se realize por completo. A obra termina, nas palavras do narrador, com um capítulo só de 
negativas. Brás Cubas não se casa; não consegue concluir o emplasto, medicamento que imaginara criar para conquistar a glória na sociedade; acaba se tornando deputado, mas seu desempenho é medíocre; e não tem filhos.

A força da obra está justamente nessas não-realizações, nesses detalhes. Os leitores ficam sempre à espera do desenlace que a narrativa parece prometer. Ao fim, o que permanece é o vazio da existência do protagonista. É preciso ficar atento para a maneira como os fatos são narrados. Tudo está mediado pela posição de classe do narrador, por sua ideologia. Assim, esse romance poderia ser conceituado como a história dos caprichos da elite brasileira do século XIX e seus desdobramentos, contexto do qual Brás Cubas é, metonimicamente, um representante.

Na obra estudada de Machado de Assis aqui analisada/estudada pode-se destacar situações provocativas que estão relacionadas com a ciência, as linguagens cotidiana e científica e o ensinar e o aprender Ciências, e se encaixam como a mão e a luva na intenção de refletir sobre o uso da literatura no ensino. A obra desperta nossa atenção para questões como: Brás Cubas tenta construir o emplasto e nos traz a oportunidade de discutir o uso de medicamentos "enunciados pelo narrador e também os (medicamentos) que são utilizados pela sociedade contemporânea", com suas especificidades, e as características da linguagem científica e sua importância na aprendizagem de Ciências.

Partindo desse pressuposto, neste trabalho de caráter exploratório temos como objetivo descrever uma atividade didática pautada em interações entre a literatura clássica brasileira e o ensino de ciências, estabelecidas pelos estudantes de educação básica através de um estudo de caso, no qual os estudantes interagiram, durante a execução de atividades, fundamentadas na interdisciplinaridade entre literatura e ciências, em busca da melhor solução para casos investigativos de forma colaborativa. Dessa forma, pretendemos contribuir para a evolução de estudos que envolvam a literatura clássica brasileira e o ensino de ciências, a partir da investigação das interações entre os estudantes, considerando estas como um processo social, no qual há o compartilhamento de informações, a promoção de atitudes relacionadas ao respeito e à valorização das opiniões dos colegas e a divisão da responsabilidade sobre o aprendizado. 


\section{A argumentação científica para o ensino de ciências}

Pesquisas na área do ensino de ciências têm apontado que a argumentação científica não ocorre de maneira espontânea para muitos educandos, mas somente por meio da prática (OSBORNE, 2004; DAWSON e VENVILLE, 2010). Existem autores que acreditam que instruir os alunos sobre "como argumentar" não tem efeito em relação ao desenvolvimento de habilidades argumentativas (KNUDSON, 1991; KNUDSON, 1992), enquanto há os que afirmam que essa instrução melhora a qualidade de argumentação (CHO e JONASSEN, 2002; DAWSON e VENVILLE, 2010; KUHN, 2010; REX et al., 2010). Pode-se citar as pesquisas que investigam estratégias utilizadas por professores para promover a argumentação em sala de aula, sem que sejam necessariamente associadas a elas instruções aos alunos sobre "como argumentar" (TEIXEIRA, 2005; SIMON et al., 2006).

O presente trabalho buscou contribuir para o aprofundamento da discussão sobre a seguinte questão: o ensino em sala de aula sobre os componentes que usualmente estão presentes em um "bom” argumento favorece a elaboração de argumentos de melhor qualidade por parte dos alunos? Elementos capazes de responder ao questionamento foram buscados por meio da aplicação de uma proposta de ensino pautada na resolução de casos investigativos (SÁ e QUEIROZ, 2007), que se distingue de outras pela adoção do Esquema de Argumento de Toulmin (2001) como instrumento de ensino visando ao aprimoramento da habilidade de argumentação.

A opção pela utilização do método de estudo de casos se deve por ser apontado como capaz de estimular a argumentação em situações de ensino de ciências (SÁ e QUEIROZ, 2010; SÁ e QUEIROZ, 2007), oferecendo aos alunos a oportunidade de direcionar sua própria aprendizagem por meio de discussões que envolvem aspectos científicos e sociocientíficos presentes nos casos.

Os argumentos produzidos na resolução dos casos foram analisados com base no Esquema de Argumento de Toulmin (2001), também conhecido como Toulmin's Argument Pattern (TAP), como mostra a figura 1, e em adaptações feitas à metodologia de análise da qualidade dos argumentos proposta por Erduran et al. (2004). 
Figura 1: Esquema de Argumento de Toulmin (2001, p.250).

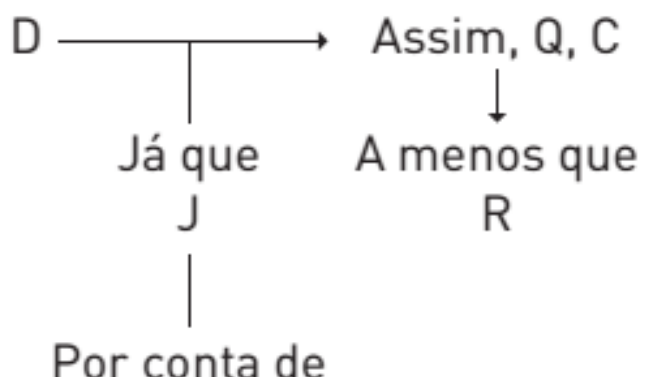

B

Segundo Toulmin (2001), os elementos fundamentais de um argumento são o dado (D), a conclusão (C) e a justificativa (J). É possível apresentar um argumento, contando apenas com esses elementos, cuja estrutura básica é: “a partir de um dado D, já que J, então C". Porém, para que um argumento seja completo, pode-se especificar em que condições a justificativa apresentada é válida ou não, indicando um peso para tal justificativa. Dessa forma, podem ser acrescentados ao argumento qualificadores modais (Q), ou seja, especificações das condições necessárias para que uma dada justificativa seja válida. Da mesma forma, é possível especificar em que condições a justificativa não é válida ou suficiente para dar suporte à conclusão. Neste caso, é apresentada uma refutação (R) da justificativa. Além dos elementos já citados, a justificativa, que apresenta um caráter hipotético, pode ser apoiada em uma alegação categórica baseada em uma lei, por exemplo. Trata-se de uma alegação que dá suporte à justificativa, denominada backing (B) ou conhecimento básico. O backing é uma garantia baseada em alguma autoridade, uma lei jurídica ou científica, por exemplo, que fundamenta a justificativa. Dessa forma, foi considerado como "bom" argumento aquele que se alinha de maneira favorável com as expectativas expressas pela metodologia em questão.

\section{Procedimentos metodológicos}

A presente pesquisa foi desenvolvida na disciplina de ciências no $8^{\circ}$ ano do Ensino Fundamental em uma escola pública municipal de Volta Redonda, Rio de Janeiro, Brasil. A disciplina, apesar de tratar conteúdo específicos de ciências, tem entre seus principais objetivos o desenvolvimento de habilidades de comunicação oral e escrita dos estudantes. A proposta do estudo de caso foi aplicada em alunos de uma turma de 35 alunos, com o 
acompanhamento do professor, que também é o pesquisador e foi o responsável pela coleta dos dados analisados.

Os alunos foram incumbidos de solucionar um caso investigativo de caráter sociocientífico baseado em uma narrativa da obra Memórias póstumas de Brás Cubas de Machado de Assis e apresentar oralmente a resolução do caso, que foi subdividido em várias atividades. Porém, em uma delas, a apresentação oral foi precedida pela realização, por parte dos alunos, de quatro atividades que visavam torná-los conhecedores dos elementos que constituem um "bom" argumento, na perspectiva de Toulmin (2001), enquanto que na outra a argumentação foi espontânea e nenhuma orientação sobre "como argumentar" foi ministrada.

$\mathrm{O}$ caso foi elaborado nos moldes do gênero textual carta e inspirado no livro de Machado de Assis, Memórias Póstumas de Brás Cubas. O Estudo de caso foi estruturado de modo que apresentassem questões sociais, ambientais, econômicas e/ ou éticas, com o intuito de estimular no aluno a capacidade de tomar decisões e argumentar diante de problemas da vida real. A seguir, o estudo de caso que foi dado aos alunos:

\section{Estudo de caso: "Emplasto Brás Cubas?"}

Domingo, 14 de março de 1880

Fiquei alguns dias sem escrever, pois faltava-me ânimo, vontade e energia. A semana passou, com ela chegou o final de semana tão esperado, mas alguns sentimentos que povoavam meu coração não me abandonavam.

Domingo, dia do ócio? Ou dia do despertar? Para mim, este domingo tem um sabor especial. Saí para uma caminhada no quarteirão de minha casa e ao olhar para as pessoas nas ruas, algumas ideias surgiram... Será que os sentimentos de angústia, tristeza, melancolia e tédio que algum tempo vinha sentindo era comum aos mortais que passavam por mim sorrindo, brincando, conversando, paquerando? Lembrei-me de Shakespeare que dizia, "Todo mundo é capaz de dominar uma dor, exceto quem a sente".

Continue a minha caminhada refletindo sobre tudo o que eu sentia e o que provavelmente muitos jovens, adultos, idosos sentiam também. Às vezes, nos escondemos por trás de sorrisos, brincadeiras e piadas. Porém, o que habita em nosso coração e em nosso pensamento só não escondemos de nós mesmos.

Olhando as construções, as paisagens e os estabelecimentos, deparo-me com um letreiro "Pharmacia". Foi neste momento, que eu, Brás Cubas, tive uma ideia genial. Uma ideia que poderia trazer para mim a glória, o esplendor. Não é um sinal? Hoje é domingo, primeiro dia da semana... Dia da glória! Dia de glória!

Voltei a passos largos para minha casa e comecei a rascunhar minhas ideias. Um emplasto! Essa ideia é nada menos que a invenção 
de um medicamento sublime, um emplasto anti-hipocondríaco, destinado a aliviar a nossa melancólica humanidade.

$O$ que me influi principalmente é o gosto de ver impressas nos jornais, mostradores, folhetos, esquinas, e enfim nas caixinhas do remédio, estas três palavras: "Emplasto Brás Cubas". Para que negálo? Não posso negar também, o lucro que irei obter na comercialização desse medicamento.

Novamente, me transportei para a "Pharmacia" e visualizei as caixinhas de emplasto nas prateleiras e os clientes procurando pelo medicamento que aliviaria essa melancolia que assola a humanidade. "Por gentileza, quero um caixinha do emplasto Brás Cubas".

Agora, este projeto precisa sair do papel. Por onde começar? A quem poderei compartilhar a ideia mais genial que tive nos últimos tempos? Para quem não estava conseguindo nem pensar nos últimos dias, este domingo, foi o domingo do despertar.

Brás Cubas é o personagem principal da obra "Memórias Póstumas de Brás Cubas", de Machado de Assis.

A seguir, são descritas cada uma das atividades realizadas na turma, na sequência em que foram aplicadas.

a) Jogo argumentativo: Foram formados grupos que trabalharam por um período de quinze a vinte minutos na elaboração de um bom argumento sobre o porquê da personagem principal da obra de Machado de Assis criar o emplasto que pretendia criar para curar a melancolia. Explicou-se que as razões para o merecimento do medicamento poderiam ser reais ou imaginárias, formais ou informais. Durante a execução da tarefa, cada grupo selecionou um integrante para redigir os argumentos formulados e um porta-voz para apresentá-los. O professor, até então, não exercera nenhuma influência sobre os argumentos dos alunos. Esgotado o período de vinte minutos, cada grupo apresentou para a turma as suas razões para merecer o prêmio. Após a apresentação dos grupos, um material com definições e exemplos de componentes argumentativos, segundo Toulmin (2001), foi entregue a cada um deles. Com o apoio desse material, os alunos tentaram identificar a existência desses componentes nos argumentos por eles elaborados para justificar o merecimento do grupo ao prêmio. Ou seja, os alunos tentaram identificar tais componentes em seus próprios argumentos, que foram também analisados pelo professor. Na aula seguinte, este expôs em slides a sua análise sobre os argumentos formulados por cada um dos grupos, seguindo o TAP. Dessa forma a turma pôde visualizar as similaridades e diferenças entre os argumentos usados pelos diferentes grupos e, finalmente, chegar a um consenso sobre o paciente que mereceria o medicamento. 
b) Identificação de componentes argumentativos em artigos de divulgação científica: consistiu na solicitação aos alunos para que identificassem argumentos presentes em artigos de divulgação científica relacionados à fosfoetanolamina, seja no campo ético, relacionado a sua liberação e com relação a seu possível efeito de cura do câncer e toda sua trajetória de discussão no Brasil, estabelecendo relações com o emplasto Brás Cubas. Foram extraídos artigos das revistas Galileu, Superinteressante e Scientific American Brasil. Os alunos foram distribuídos em pequenos grupos e receberam Esquemas de Argumento de Toulmin (2001) em branco. Os esquemas deveriam ser preenchidos com os componentes identificados nos argumentos localizados nos artigos.

c) Texto argumentativo sobre a resolução do caso: consistiu na solicitação de elaboração de um texto argumentativo a respeito da solução apontada como sendo a mais viável para o caso proposto a cada um dos grupos. Observações a respeito da presença ou ausência de componentes argumentativos nos textos foram realizadas. Os textos corrigidos foram devolvidos aos grupos e foi solicitada a sua reformulação com base nas observações feitas.

A coleta dos dados analisados foi realizada por meio dos seguintes procedimentos: filmagem das apresentações orais dos alunos sobre a resolução dos casos e suas falas transcritas, de modo a preservar ao máximo suas características originais para posterior análise; "diário do caso" produzido por cada um dos grupos, cujas informações foram sintetizadas e comparadas às resoluções apresentadas para os casos.

A análise comparativa da estrutura dos argumentos identificados nas apresentações orais de grupos pertencentes à turma foi realizada com base nos referenciais teóricos citados. Neste artigo apresentamos, inicialmente, o resultado da análise dos argumentos empregados pelos estudantes na resolução do caso interdisciplinar com a literatura clássica brasileira.

\section{Resultados e discussão}

O problema a ser resolvido está definido no caso e relacionado com a supervalorização que as pessoas, de um modo geral, dão aos medicamentos, colocando-os muitas vezes como um recurso capaz de resolver todos os males que podem acometer o ser humano. O caso é adaptado do romance de Machado de Assis, Memórias Póstumas de Brás Cubas. No trecho apresentado como estudo de caso, Brás Cubas coloca toda a sua ansiedade para "resolver" a melancolia da humanidade através de um medicamento milagroso, o emplasto Brás Cubas. As 
principais características do caso estão pautadas no fato da busca da fama, almejada por Brás Cubas e a resolução dos problemas das pessoas através de sua suposta descoberta do Emplasto Brás Cubas.

O tema do uso dos medicamentos é relevante e atual, e a aplicação do caso em sala de aula tem utilidade pedagógica, pois pode promover a compreensão sobre a importância do uso consciente de remédios, assim como sobre a necessidade de perceber todos os preceitos éticos que estão envolvidos na utilização e fabricação de novas drogas. O caso é pouco extenso, o que pode também favorecer sua abordagem e, além disso, faz referência à obra literária de Machado de Assis em uma linguagem de fácil acesso.

As pessoas têm por hábito chamar os fármacos de remédios. Entretanto, a origem da palavra latina remediare é remediar e não curar. Assim, atualmente deve-se utilizar os termos fármacos ou medicamentos, sendo a distinção se refere à natureza do princípio ativo. $\mathrm{O}$ fármaco que, uma vez formulado, torna-se elemento constitutivo do medicamento que é consumido. Esta terminologia é mais correta por traduzir melhor o papel desempenhado pelos fármacos disponíveis no arsenal terapêutico moderno, capazes de efetivamente curar, mais do que remediar.

Uma saída para amenizar amenizar o problema da automedicação é formar pessoas com capacidade crítica, que possam opinar criticamente sobre as influências da cultura, da mídia e dos problemas da saúde pública sobre o uso de medicamentos por conta própria que pode ter aspectos positivos, quando feito de forma consciente, ou aspectos negativos, quando feito inconscientemente. A compra de medicamentos inadequados implica no risco de um tratamento ineficaz, visto que a maioria das pessoas desconhece os efeitos colaterais provocados pelos medicamentos.

As obras literárias, em especial os clássicos, trazem abordagens científicas a fim de caracterizar os personagens, seja através de suas moléstias, seja a partir de uma contextualização histórica das mesmas. Na obra "Memórias Póstumas de Brás Cubas" de Machado de Assis, o personagem tem o projeto de criar um emplasto para curar a melancolia da sociedade.

Durante várias passagens do enredo, Brás Cubas faz inúmeras indagações sobre a criação desse medicamento. Seus desejos vão além dos benefícios do emplasto, visto que deseja também o lucro e a fama com a venda do produto. 
O caso foi estudado em cinco aulas, com duração de cinquenta minutos, sendo que seria muito importante que pudesse ser trabalhado nas aulas de Ciências Naturais e Literatura, proporcionando uma interdisciplinaridade necessária ao Ensino Básico.

Nesta análise, os três grupos encarregados de solucionar o caso serão, de agora em diante, denominados de G1, G2 e G3, G4, G5, G6 e G7. Cada grupo possuía cinco alunos, alunos que se organizaram em função das afinidades que compartilhavam, sem qualquer interferência externa dos pesquisadores.

Começando a análise pela solução apontada pelos grupos para resolver o caso, verificamos que o grupo G7 não indicou nenhuma solução e os grupos G3 e G4 chegaram à mesma conclusão: a personagem principal teria que conseguir a fórmula do seu emplasto para curar-se da melancolia. Dois dos grupos, G2 e G5, chegaram à mesma conclusão: remédios não curam o problema, terapias e amigos seriam as melhores soluções. Já o grupo G1 e G6, embora tenham apresentado uma série de dados a respeito de diferentes alternativas de prevenção para o caso proposto, concluiu a sua apresentação sem indicar a melhor alternativa para resolver o problema. Quanto à pertinência dos argumentos empregados pelos grupos na resolução dos casos, verificamos que as informações por eles fornecidas são condizentes com as fontes de pesquisa citadas no "diário do caso".

Algumas análises dos argumentos são apresentadas a seguir.

\section{Componentes do argumento identificados na resolução do caso}

As análises selecionadas foram dos grupos G1, G2, G4 e G7. Esta escolha se deve ao fato dos grupos G3, G5 e G6 terem chegado a conclusões semelhantes aos outros, como foi relatado na seção anterior. Contudo, a argumentação foi mais baixa, o que não nos forneceria dados suficientes para a discussão.

O G7 não apontou nenhuma solução, seu argumento se baseava em uma reescrita da carta de maneira afirmativa/explicativa. Os componentes do grupo apontaram como resolução

um relato do caso, quando afirmaram: "Brás Cubas queria criar um remédio que curasse a sua tristeza".

A resolução do caso do G4 teve o seguinte dado (D): “a personagem principal estava buscando uma cura para a sua melancolia através da criação do emplasto Brás Cubas, um remédio com o mesmo nome da personagem principal”. O qualificador modal (Q) e a conclusão (C) foram identificados em: "portanto, o Brás Cubas deve se tornar um cientista 
através de muitos estudos com outros cientistas da área ou alguém de uma farmácia”. Como refutação $(\mathrm{R})$, os alunos relataram em seus argumentos: "A menos que o Brás Cubas tenha sido um cientista e não tivesse tido tempo para fabricar o emplasto que ele tanto queria". Como justificativa (J) a essa conclusão, os alunos afirmaram: "Já que o Brás Cubas estava morto e possa ter tirado a própria vida pela sua melancolia".

O G2 fez uma ampla reflexão quanto ao uso de medicamentos, de maneira indiscriminada os alunos colocaram como dado (D): "Na carta que lemos, o Brás Cubas estava muito triste, muito sem saber o que fazer e em um ato de desespero queria curar um estado de melancolia que possuía". Como conclusão (C), os alunos afirmaram: "Assim, o Brás Cubas não entendia que o emplasto não era tão simples como um estalar de dedos, era necessário que ele cuidasse da sua mente e isso é muito complexo". Como refutação $(\mathrm{R})$ à conclusão, os alunos escreveram: “A menos que o emplasto seja utilizado com outras coisas que não são remédios". Como justificativa (J), foi relatado: “quando existem problemas de depressão ou até um câncer, causando melancolia é muito importante o contato com a família”. Como backing (B) para essa resposta, os alunos escreveram: "É só lembrar do caso da fosfoetanolamina, foi anunciado que tinha sido descoberto um remédio da cura do câncer, enchendo as pessoas de esperança mas não funcionava, podendo levar elas para um estado maior ainda de melancolia".

O argumento do G1 apresentou o seguinte dado (D): “o Brás Cubas estava muito triste e melancólico e pode estar com depressão". A justificativa (J) que o grupo apresentou foi a seguinte: "a ciência pode salvá-lo mas ainda é necessário ter cuidados além do remédio". Foi identificado um backing (B) no argumento de conclusão (C), quando afirmaram: "o caso da fosfoetanolamina foi muito triste, às vezes a ciência pode nos enganar”.

\section{Considerações finais}

Ciência e literatura, apesar de terem linguagens específicas e métodos próprios, ficaram valorizadas quando postas em interação, proporcionando diferentes leituras e novas perspectivas de análise e de trabalho. Este trabalho evidenciou um diálogo possível entre saberes diversos ao olhar para um exemplo da nossa literatura de um autor renomado, Machado de Assis, e fazer emergir sentidos que proporcionam uma compreensão global.

Recorremos à teoria de argumentos de Toulmin (2001) para, de forma breve, justificar a possibilidade de interdisciplinaridade entre essas duas áreas do conhecimento. Apresentamos 
ainda algumas implicações deste diálogo de saberes para a escola, particularmente para a educação em ciência.

De uma visão do mundo compartimentado em explicações fragmentadas, caminhamos em direção à necessidade cada vez maior de pensamento holístico. As habilidades de comunicação foram analisadas de forma que os argumentos construídos trocados entre os estudantes durante a resolução do estudo de caso na foram classificadas seguindo a Argumentação de Toulmin (2001). Os argumentos dos grupos mostram que as habilidades mais recorrentes durante a resolução foram a importância de buscar ajuda para a cura da melancolia além do emplasto sugerido pela personagem. Porém, em intensidades diferentes, o que conferiu o grupo mais participativo um argumento mais sólido, identificando as várias etapas propostas por Toulmin (2001).

Conforme já mencionado, a argumentação foi recorrente durante as discussões, o que pode ser confirmado pelos argumentos apresentados anteriormente. Mesmo esta pesquisa não estando desprovida de limitações, como o restrito número de sujeitos pesquisados, e a falta de costume dos alunos com essa atividade, concluímos que tal resultado sugere a potencialidade das atividades na promoção de argumentos para a formação de cidadãos ativos.

\section{Referências}

CHO, K.; JONASSEN, D.H.The effects of argumentation scaffolds on argumentation and problem solving. Educational Technology Research and Development, v. 50, n. 3, p. 5-22, 2002.

DAWSON, V. M.; VENVILLE, G. Teaching strategies for developing students' argumentation skills about socioscientific issues in high school genetics. Research in Science Education, v. 40, n.2, p. 133-148, 2010

KNUDSON, R. E. Effects of instructional strategies, grade and sex on student's persuasive writing. Journal of Experimental Education, v. 59, n. 2, p.141-152, 1991.

KNUDSON, R. E. The development of written argumentation: An analysis and comparison of argumentative writing at four grade levels. Child Study Journal, v. 22, n.3, p. 167184, 1992.

KUHN, D. Teaching and learning science as argument. Science Education, v. 94, n. 5, p.810$824,2010$.

OSBORNE, J.; ERDURAN, S.; SIMON, S.; MONK, M.Enhancing the quality of argumentation in school science. Journal of Research in Science Teaching, v. 41, n. 10, p. 994-1020, 2004.

REX, L. A.; THOMAS, E. E.; ENGEL, S. Applying Toulmin: teaching logical reasoning and argumentative writing. English Journal, v. 99, n. 6, p. 56-62, 2010. 
SÁ, L.P.; QUEIROZ, S.L. Promovendo a argumentação no ensino superior de química. Química Nova, v. 30, n. 8, p. 2035-2042, 2007.

SÁ, L.P.; QUEIROZ, S.L. Estudo de casos no ensino de química. Campinas: Editora Átomo, 2010.

SIMON, S.; ERDURAN, S.; OSBORNE. J. Learning to teach argumentation: research and development in the science classroom. International Journal of Science Education, v. 28, n. 2-3, p. 235-260, 2006.

TEIXEIRA, F.M. Atividades promotoras de argumentação nas séries iniciais: o que fazem os professores? In: V ENCONTRO NACIONAL DE PESQUISA EM EDUCAÇÃO EM CIÊNCIAS, 5., 2005. Bauru. Atas... Bauru, p.1-11, 2005.

TOULMIN, S. Os usos do argumento. Trad. Reinaldo Guarany. São Paulo: Martins Fontes, 2001

Autores

Lucas Peres Guimarães

Doutorando do Programa de Pós Graduação em Ensino de Ciências do Instituto Federal de Educação, Ciência e Tecnologia (IFRJ) Nilópolis, Rio de Janeiro, Brasil

Professor de Educação Básica da Rede Municipal de Barra Mansa, Rio de Janeiro, Brasil

Denise Leal de Castro

Docente do Programa de Pós Graduação em Ensino de Ciências do Instituto Federal de Educação, Ciência e Tecnologia (IFRJ) Nilópolis, Rio de Janeiro, Brasil 